that regulate spectrum-sharing to free up $500 \mathrm{MHz}$ for wireless broadband use by 2020 . In November 2012, a company that later evolved into Ligado filed a request to share the 1,675-1,680-MHz band.

Commercial mobile-phone companies are already transmitting at slightly lower frequencies, the 1,670-1,675-MHz band - a situation that has caused problems with NOAA data.

In a representative sample of GOES imagery taken between May and September 2015, the agency found that $3.6 \%$ of the data during that stream had been subject to interference. And in May of this year, NOAA clocked 30 events in which satellite transmissions had dropped out, either streaking or nearly obliterating the images. "We consider that to be unacceptable," Wissman says.

In response, NOAA has begun to shift the transmission frequencies for the radiosonde balloons it launches to obtain vertical profiles of the atmosphere. It also redesigned an aspect of its GOES-R transmissions to be centred on $1,686.6 \mathrm{MHz}$, in the hope that this would be high enough to escape the interference.

But that change affects only how GOES-R relays its own imagery to Earth. GOES-R has a second job as a sort of internet in the sky, relaying data from 27,000 ground stations including stream gauges, tsunami buoys and seismic stations (see 'Weather watchers'). If Ligado's application is granted, that 'rebroadcast' service is likely to be interrupted - affecting forecasts of phenomena such as the spread of smoke during wildfires or the disruption of plane flights by volcanic ash.

"It's just an untenable situation to have in a critical situation," says William Mahoney, an atmospheric scientist at the National Center for Atmospheric Research in Boulder,

\section{WEATHER WATCHERS}

The US government's Geostationary Operational Environmental Satellite (GOES) system monitors atmospheric and surface conditions in the continental United States - collecting data that power the country's weather forecasts.

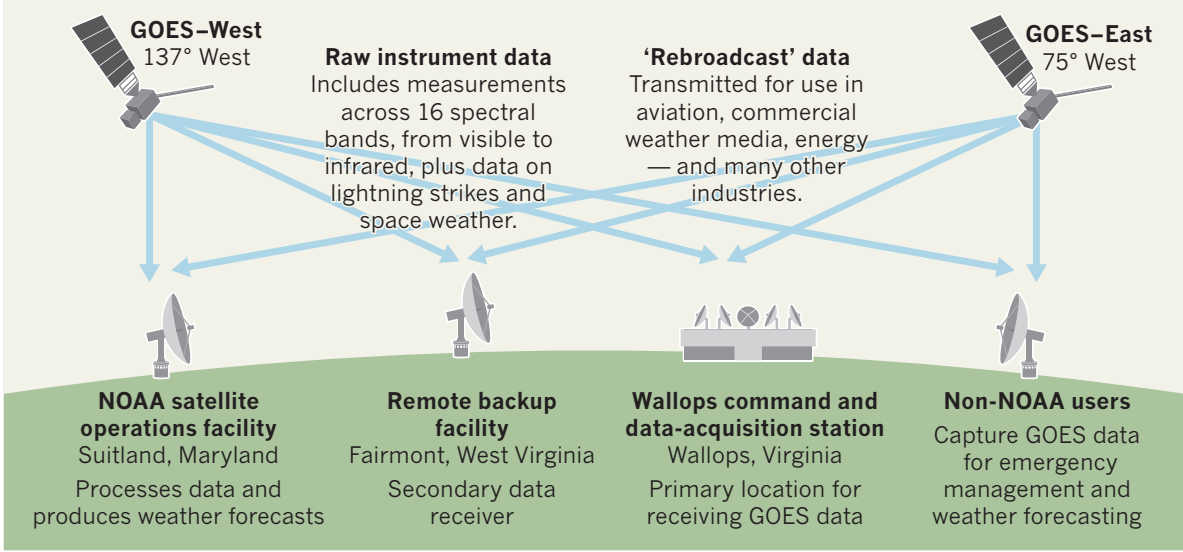

Colorado, and head of the AMS commission on the weather, water and climate enterprise.

One of GOES-R's big advantages is that it will send updated data as often as every 30 seconds. That's much more frequent than the 10-30-minute refresh time of the current GOES series, so any disruption to the real-time data flow will be much worse, Porter says.

Ligado has proposed ways to address the concerns, such as establishing blackout zones around NOAA's receiving stations or creating a cloud-based computing network to handle data distribution for non-NOAA users.

But many of those who have commented publicly are sceptical about such plans. The World Meteorological Organization pointed out that cloud computing is vulnerable when weather data are most needed: during severe storms.
The FCC is accepting replies to the original set of public comments until 21 July. After that, it will grind slowly towards a decision.

In Tuscaloosa next week, meteorologists will sit down for a public discussion with representatives from Ligado about the best way forward. Porter, who will chair the panel, hopes that the government will proceed slowly - perhaps by delaying the bandwidth-sharing or at least phasing it in slowly and documenting any interference.

"This is not just, 'Oh, a few weather forecasts,' says Renee Leduc Clarke, a consultant with Narayan Strategy in Washington DC who has been working with clients on the spectrum-sharing issue. "This is equal to lives and property inside our economy the same economy we're trying to boost with wireless broadband." -

\section{Brain-data gold mine released}

\section{Massive survey of mouse visual-cortex activity aims to reveal brain's computational rules.}

\section{BY HELEN SHEN}

I nspired by the large-scale sky surveys with which astronomers explore the cosmos, neuroscientists in Seattle, Washington, have spent four years systematically surveying the neural activity of the mouse visual cortex. The Allen Brain Observatory's first data release, on 13 July, provides a publicly accessible data set of unprecedented size and scope, designed to help scientists to model and understand the human brain.

The project is part of an ambitious ten-year brain-research plan announced in 2012 by the
Allen Institute for Brain Science. Designed to catalogue neurons and their electrical characteristics in minute detail, the initiative aims to enable new insights into how perception and cognition arise.

To compile the brain observatory's first data set, researchers used a specialized microscope to record calcium waves that occur when neurons fire, sampling activity in 25 mice over 360 experimental sessions, while the animals viewed a battery of visual stimuli such as moving patterns of lines, images of natural scenes and short movies. The data set so far includes 18,000 cells in 4 areas of the visual cortex, making it one of the largest and most comprehensive of its kind. The set also includes information about each neuron's location and its expression of certain genetic markers. At 30 terabytes, the raw data are too large to share easily, but users can download a more manageable processed data set, or explore it online.

"It's amazing," says Anne Churchland, a neuroscientist at Cold Spring Harbor Laboratory in New York. “There's no other effort I know of where people have looked at so many brain areas with so many stimuli - and importantly, where the data are freely available as well." 


\section{NEWS INFOCUS}

\section{CORRECTION}

The article 'Interference puts satellite data at risk' (Nature 535, 208-209; 2016)

wrongly stated that William Mahoney would lead a panel on spectrum-sharing at an American Meteorological Society meeting later this month. Jonathan Porter is the panel chairman. In addition, it did not make it clear that Ligado Networks is a satellitecommunications company. 